\title{
Sobre teoría fotográfica en Aisthesis
}

\author{
José Pablo Concha Lagos
}

Instituto de Estética, Facultad de Filosofía, Pontificia Universidad Católica de Chile. jconchal@uc.cl

La fotografía como objeto de estudio recién aparece en el año 1998 en el Instituto de Estética, cuando se dicta por primera vez un curso dedicado exclusivamente a esta disciplina: a partir de ese año, el profesor Gonzalo Leiva comienza a enseñar el curso "Historia de la Fotografía Chilena", el cual perdura hasta hoy. Actualmente, además, se completa la oferta fotográfica con clases como "Estética de la Fotografía", que forma parte de la malla de cursos mínimos de la Licenciatura, así como los talleres de fotografía documental y fotografía latinoamericana. A esta línea particular se le agregan también clases que tienen a la fotografía como elemento relevante, dentro de una visualidad más amplia, como el curso "Iconografías de América". Esta presencia de cursos y seminarios es el reflejo de la importancia que paulatinamente fue adquiriendo el problema de la visualidad en el marco de la fotografía, en un contexto que en principio no aceptaba fácilmente darle categoría académica a este objeto de estudio.

En este sentido, no sorprende que la preocupación teórica de este fenómeno fuera tardía tanto en el Instituto de Estética como en el contexto cultural chileno. Si bien la formación de fotógrafos en Chile se profesionaliza en la década de los ochenta, esta está circunscrita al ámbito técnico-profesional; su ingreso a la academia se comienza a dar tímidamente recién a finales de los años noventa. Por lo tanto, el contexto crítico que se espera otorgue la reflexión universitaria se configurará algo tardíamente. La producción puramente especulativa, teórica y abstracta en nuestro espacio cultural tendrá un primer volumen significativo en el año 1980, con la publicación del libro de Ronald Kay, Del espacio de acá. Señales para una mirada americana. Este breve texto, muy influido por la filosofía alemana de mediados del siglo $\mathrm{xx}$, es de gran importancia por su originalidad: reflexiona filosóficamente sobre un objeto que la 
academia había obliterado de manera sistemática. Circuló escasamente y tuvo un impacto más bien acotado a las artes visuales, ya que criticaba severamente la tradición plástica chilena en favor de la fotografía. Desde la publicación de este libro, en los años ochenta, hasta que aparece por primera vez un artículo sobre fotografía en Aisthesis, pasarán veintiún años. En el intertanto, al interior del Instituto de Estética, el creciente interés por esta área de estudio se manifestará en la realización, con financiamiento acreditado, de investigaciones académicas que se aproximan a la fotografía desde diversas miradas; por ejemplo, a partir de una perspectiva antropológica visual, como las investigaciones lideradas por la profesora Margarita Alvarado; o desde una perspectiva histórica, como las realizadas por el profesor Gonzalo Leiva; o desde la transdisciplina, como las realizadas por la profesora Valeria de los Ríos; o de corte más especulativo, como las realizadas por mí. Hoy, la fotografía tiene un espacio asegurado dentro del Instituto de Estética.

En este contexto, Aisthesis ha sido una revista muy abierta a recibir aportes relativos a la fotografía. Como ya decíamos, en el año 2001 se publica el primer artículo dedicado exclusivamente a este tema, en donde se aborda la compleja relación entre la imagen fotográfica y el lenguaje; ese mismo año, se incluye también un artículo de la profesora Margarita Alvarado escrito en conjunto con Peter Mason, en el que se trabaja el asunto del retrato del indígena (del "otro"), tanto en la pintura europea del siglo XVII, como en la fotografía. Al año siguiente, en un gesto inédito, se consagra un número completo a la fotografía, volumen bajo la responsabilidad del profesor Gonzalo Leiva. Este número es especialmente significativo porque da vitrina a las investigaciones que ya se venían realizando sobre la fotografía, desde la originalidad de una perspectiva inter- y trans-disciplinaria. Es decir, la revista acogió trabajos de metodologías combinadas de la ciencias sociales y la estética.

Si nos concentramos en este número del año 2002, vemos que se ordenó temáticamente en cinco secciones: "Estética y representación fotográfica", "Estética e imaginario fotográfico", "Estética y memoria", "Investigaciones en curso" y "Miradas y lecturas". Se advierten otras secciones, pero estas corresponden a asuntos relativos al Instituto de Estética, como el artículo sobre los treinta años del Instituto escrito por su Director, profesor Fidel Sepúlveda.

$\mathrm{Al}$ concentrarnos en el contenido de estas secciones, es posible identificarlas temáticamente; la primera, por ejemplo, aborda ciertas estrategias de representación de sujetos. Los artículos que la constituyen cubren modos de representación desde el siglo XIx hasta la actualidad, es decir, desde el retrato de estudio deciminónico hasta el uso publicitario de la representación de cuerpos. Así, esta sección plantea la diversidad de posibilidades de "darse el sujeto", desde una práctica representacional "inconsciente" ideológicamente, hasta una que se muestra muy pendiente del efecto que desea provocar en el observador. Desde una perspectiva teórica, la fotografía es considerada una forma eficiente de "imaginar" al sujeto en la modalidad visual, levantándolo como figura eficaz para disponer del referente. En algunos artículos, 
como en "Anorexia", del profesor Pablo Corro, la observación es particularmente aguda al desmantelar y revelar el objetivo oculto de una campaña publicitaria. Acá, la fotografía es analizada desde una punto de vista crítico, mostrando la capacidad ideológica del uso de la fotografía.

Un artículo especialmente interesante de esta sección es el de la profesora del Instituto de Estética de la UNAM, Laura González, quien estudia la fotografía desde un ángulo filosófico al pensarla como imagen. Este acercamiento podría ser provocador, ya que es posible creer que considerar la fotografía como imagen es una redundancia, pero esto no es así. Lo que hay que entender es que la fotografía es un tipo particular de imagen, pues posee un carácter técnico que, al ser capaz de aportar un contenido ideológico clave, determina su significado. Esta calidad técnica ha sido objeto de comprensión diversa a lo largo del desarrollo de la teoría de la fotografía y de lo que el sentido común dice sobre ella. Por un lado, la imagen fotográfica pareciera ser el resultado de la puesta en marcha de un dispositivo que aseguraría la objetividad de lo producido; por lo tanto, el sentido común dice: la fotografía es objetiva. Por otro lado, un análisis más riguroso plantea que lo técnico es esencialmente ideológico y cualquier producto salido de él acarrea el mismo significado.

El artículo de la profesora González se debate entre estos dos campos. Argumenta que el rasgo esencial de la fotografía es su indicialidad; es decir, el contacto directo entre el referente y la imagen. Aquí debemos precisar que el dispositivo numérico binario de producción de imagen aún no sustituía definitivamente, como hoy, a la fotografía analógica. Este punto muestra un elemento fundamental de la práctica: la dependencia del dispositivo técnico al ámbito económico-comercial. Es decir, el mercado determina gravemente el punto de vista que debemos tener al analizar la imagen fotográfica. Este dispositivo es resultado del aparato industrial y desde este lugar se puede pensar como encarnación radical de su tiempo y de la ideología dominante. Si en este artículo se plantea la indicialidad como rasgo clave; la visión crítica que se presenta acá queda circunscrita a un planteamiento más bien introductorio.

En la sección "Estética e imaginario fotográfico", la fotografía cobra valor desde la perspectiva antropológica y memorialista. La imagen fotográfica sería capaz de constituirse en un memorial. Al pensar esta posibilidad, advertimos que es precisamente la calidad indicial e icónica lo que configura su potencia memorialista. Se puede actualizar, a través de la fotografía, el lugar, acontecimiento o sujeto que se desea recordar en su potencia existencial, ya que la fotografía es su constatación eficiente de realidad. La profesora Margarita Alvarado trabaja con un conjunto de fotografías de las salitreras, con la intención de reconocer la capacidad de estas imágenes de convertirse en un memorial. La fotografía es memoria porque es capaz de transformarse en la actualización de una experiencia y tiene la fuerza para homogeneizar al referente, transformando una particularidad en un objeto colectivo. La profesora Alvarado, indicando que la fotografía es "representación de la realidad", nos dirá que las imágenes de las salitreras se transforman en recuerdos que se colectivizan. Es 
decir, las fotografías testimoniales de sujetos específicos se constituyen, finalmente, en memorial de la experiencia colectiva de lo vivido en su tiempo.

El artículo de Andrea Cuarterolo, "La visión del cuerpo en la fotografía mortuoria", aborda un tópico clásico en la fotografía: la relación entre la imagen fotográfica y la muerte. Ejemplos del interés que ha despertado este tema son los gestos de Hippolyte Bayard (siglo XIx), quien pone en escena su propia supuesta muerte, y de Roland Barthes, quien, en La cámara lúcida (1980), expone el dolor que le causa la muerte de su madre. En este artículo en particular, se discute la hoy extinta tradición de fotografiar a los muertos, la cual surgió, según la autora, en los inicios de la fotografía y perduró hasta la primera parte del siglo xx. ¿Por qué ha desaparecido esta tradición? Una posible respuesta, según Cuarterolo, es que hasta mediados del siglo pasado, la relación que occidente tenía con el cadáver era más orgánica: este se entendía como parte constitutiva del sujeto y, por eso, la fotografía del cuerpo muerto era considerada como una imagen persistente de la persona, no de sus restos. Esta relación entre cadáver y sujeto estaría ya completamente escindida, por lo que hoy este tipo de fotografía sería impracticable. Lo atractivo de este problema es que una fotografía y un cadáver nos proponen la misma pregunta: ¿cuál es el referente de este "objeto"? Tanto en la fotografía como en el cuerpo muerto, aquello que le dio su origen ha desaparecido; en ambos casos no podemos acceder al referente. Esta reflexión es muy relevante para la teoría de la fotografía, ya que pone en tela de juicio los alcances del contenido fotográfico, en tanto actualización del objeto referencial. La foto y el cadáver son superficies significativas que nos llevan no en dirección al referente, sino hacia la propia capacidad del espectador de llenar de sentido esa superficie; es decir, el significado no está en la imagen, sino en quien la observa. Esta idea es central para replantearse la capacidad icónico-indicial de la fotografía, que hasta el momento se había considerado como la característica que define lo fotográfico. Sin embargo, si no hay relación referencial, la imagen es solo superficie.

El mismo rendimiento teórico, desde una perspectiva diversa, es el que se encuentra en el artículo que presenta Boris Kossoy, reconocido historiador de la fotografía brasileña. Kossoy pretende reconsiderar la historia de la fotografía, instalando a la producción latinoamericana, persistentemente olvidada, como parte de la historia general de este arte. Además, desde un ángulo más bien materialista, plantea que, en su opinión, nunca se han considerado las "condiciones de producción" de los documentos fotográficos a la hora de estudiarlos. Esta perspectiva apunta a entender los entramados de la fotografía no solo como una sucesión de hechos puramente técnicos y estéticos, sino que además instalados en, y condicionados por, una trama histórica. Este punto de vista exige una observación muy rigurosa de las variables contextuales de producción de los fenómenos sociales que tensionan la producción fotográfica.

El artículo que yo aporté para este número tuvo por finalidad rescatar el texto antes mencionado de Ronald Kay. En una feliz coincidencia con lo planteado por Boris Kossoy, traté de darle cierta contextualización histórica y teórica al libro Del espacio 
de acá. Señales para una mirada americana. El aporte de Kay a la teoría fotográfica es de una gran originalidad. Su manera de entrar al problema que plantea teóricamente esta imagen es tomando en cuenta, muy detalladamente, las variables técnicas, pero proyectándolas filosóficamente. En este sentido, y muy tributario de Walter Benjamin, inicia una filosofía de la fotografía regional. Las consideraciones iniciales de Kay reflexionan sobre el problema del tiempo y el espacio en su concreción técnica; posteriormente, y teniendo a la vista estos aportes, entra en cuestiones de orden más cultural, como, por ejemplo, la irrupción de la fotografía en América Latina y las alteraciones icónicas que esto significaría en el imaginario regional.

En el número 38 de Aisthesis, del año 2005, me toca publicar un artículo en que trato de reflexionar sobre las variables que se ponen en juego al momento de trabajar con fotografías obtenidas desde un archivo. Esta indagación es el resultado de una investigación FONDECYT dirigida por Margarita Alvarado y de la que yo fui parte como co-investigador; nuestro objeto de análisis fueron las fotografías realizada a los indígenas fueguinos. En este contexto, el acercamiento a los archivos fotográficos reveló una serie de aspectos que se deben tener en cuenta al momento de manejar estas imágenes; por ejemplo, lo azaroso resultó ser un aspecto central, en tanto variable de existencia de una determinada fotografía al interior del depósito; también se reveló como determinante la voluntad de producir un significado de carácter ideológico por quien administra dicho espacio.

A partir del año 2005, la presencia de la fotografía en la revista se sumergirá y solo aparecerá esporádicamente en algunos artículos, pero desde un acercamiento más bien tangencial y operativo para fines diversos, ya no ceñidos a la fotografía. Es recién en el número 46, del año 2009, donde se retoma específicamente el tema, con el dossier "Fotografía y alteridad", a cargo de la profesora Margarita Alvarado y la investigadora Carla Möller. Aquí, son ocho los artículos que desde una perspectiva antropológica y, más precisamente, desde la antropología visual, abordan el fenómeno crítico de la representación del "otro". Hay que destacar que la profesora Alvarado ha liderado extensas investigaciones en este ámbito, siendo pionera -junto a sus equipos de trabajo- en revisar críticamente los presupuestos teóricos de los usos de la fotografía en las prácticas antropológicas.

En este caso, el dossier se enfrenta a una dificultad desde la perspectiva de la teoría fotográfica. En la mayoría de los artículos, la imagen es entendida como una herramienta que desaparece en el uso; es decir, los objetos de análisis son aquellos registrados por esta técnica y lo que, en general, se puede leer de ellos a través de las fotografías mismas. Hay dos excepciones relevantes: los artículos de Mariana Giordano y el de Margarita Alvarado, escrito junto a Carla Möller. El texto de Giordano comienza problematizando teóricamente los usos, alcances y riesgos de la fotografías tomadas al "otro", en tanto imágenes susceptibles de ser recontextualizadas y por esto resemantizadas, dejando de manifiesto la debilidad referencial de esta práctica. Este ángulo es especialmente importante, ya que permite establecer una distancia con la 
fuerza icónica de la fotografía. En este sentido, Giordano es clara en definir su objeto de trabajo: "no son [...] las fotografías en sí mismas, sino el sentido que ellas asumen desde la mirada del investigador perteneciente a la cultura hegemónica y desde los grupos indígenas[...]" (67). Como decíamos, esta distancia permite identificar los supuestos ideológicos presentes en la producción y, especialmente, en la distribución y lectura de las fotografías de orden antropológico. Por su parte, el artículo de Alvarado y Möller se concentra en las "modalidades de producción" de los fotógrafos Gerstmann y Quintana. Este acercamiento pone acento en asuntos que, según Kossoy, son de orden materialista; es decir, los aspectos estéticos, entendidos no desde una visión estilística, sino desde un análisis riguroso de las estrategias de producción de estos fotógrafos, que tendrá como consecuencia un correlato ideológico imaginario. En otras palabras, la estética, es decir, la propia superficie fotográfica determinada por sus propiedades lingüísticas, se advierte como vehiculadora de aspectos ideológicos en la construcción de la identidad de la alteridad "imaginada" fotográficamente.

Finalmente, en el número 52 de Aisthesis, del año 2012, se incluye un dossier dedicado a la fértil relación entre estética y técnica. Si bien los diez artículos que lo constituyen tratan diversas relaciones, tres están dedicados específicamente a la fotografía. El aporte de Ángeles Donoso toma como objeto ya no la fotografía misma, sino, casi desde una perspectiva metalingüística, los "espacios discursivos de la fotografía en Chile en el periodo de la dictadura y la transición" (407). Este artículo repasa los textos más importantes sobre fotografía producidos en aquella época. El significativo aporte de este trabajo reside, precisamente, en el análisis y catastro de la reflexión sobre fotografía durante aquel tiempo. De alguna forma, en este periodo se configura este campo y se delinea cierta ruta crítica. El artículo de Edgar Gómez Cruz, por su parte, reflexiona, en un primer momento, sobre la calidad representacional de la fotografía, lo que posteriormente se cruzará con prácticas contemporáneas de lo que denomina "Iphonegrafías". Esta propuesta actualiza la reflexión desde la novedad tecnológica, abriendo el espacio ya no a la práctica fotográfica disciplinar, sino a los usos que permiten los dispositivos digitales de comunicación contemporáneos. La fotografía, entonces, deja de ser patrimonio de los fotógrafos, y se transforma en una práctica social extendida. Para terminar, el artículo de mi autoría aborda filosóficamente los aportes del teórico francés Francois Soulages planteados en su libro Estética de la fotografía. Esta obra resulta referencial para la teoría fotográfica, porque su autor instala disciplinarmente a la fotografía en el contexto del pensamiento filosófico clásico. El aspecto que trato de desarrollar es aquel que identifica algunas fisuras en la estructura propuesta por Soulages, particularmente cuando trata de encontrar una "particularidad esencial" de la fotografía, dejando en evidencia la imposibilidad de este proyecto.

La presencia de la fotografía en la revista Aisthesis ha sido muy relevante en cuanto a hacerse cargo de un dispositivo técnico tan variable como variables son sus usos. En este sentido, la diversidad de miradas sobre la fotografía se constituye en un aporte significativo para el campo disciplinar que ella traza. 